\title{
A study on the efficacy of the recombinant Yersinia adhesin A vaccine against yersiniosis in the early phase
}

\author{
Kosuke TSUGO ${ }^{1)}$, Shin-ichi NAKAMURA ${ }^{1)}$, Hiroko YAMANAKA ${ }^{1)}$ and Yumi UNE ${ }^{1) *}$ \\ 1)Laboratory of Veterinary Pathology, School of Veterinary Medicine, Azabu University, 1-17-71 Fuchinobe, \\ Chuo-ku, Sagamihara, Kanagawa 252-5201, Japan
}

J. Vet. Med. Sci.

79(5): 855-863, 2017

doi: 10.1292/jvms.16-0528

Received: 12 October 2016

Accepted: 7 March 2017

Published online in J-STAGE:

20 March 2017
ABSTRACT. Yersinia pseudotuberculosis (Y. ptb) is a zoonotic pathogenic bacterial species of the family Enterobacteriaceae and causes yersiniosis, an acute intestinal infection in humans and animals. Y. ptb is often implicated in lethal epidemics in zoo animals and reductions in the breeding population, but a valid prevention method has not been established. Therefore, this study aimed to develop a vaccine for yersiniosis control. The immunogenicity of one of the adhesion factors involved in pathogenic mechanisms of $Y$. ptb, Yersinia adhesin A (YadA), was investigated. BALB/c mice were divided into 3 groups: in group 1, mice received insoluble recombinant YadA ( $\mathrm{rYadA})$ produced in genetically engineered Escherichia coli $(100 \mu \mathrm{g} /$ dose); in group 2, mice received inactivated Y. ptb with strong expression of YadA ( $20 \mathrm{mg} /$ dose);and in group 3, mice received phosphate-buffered saline ( $0.2 \mathrm{ml} / \mathrm{dose})$. All interventions were administered subcutaneously twice at an interval of 1 week. One week after the second administration, Y. ptb ( $10^{7}$ cells/mouse) was inoculated orally. As a result, the survival rate was $100 \%$ in group $1,60 \%$ in group 2 , and $0 \%$ in group 3 . The anti-YadA antibody titer increased in a stepwise fashion in groups 1 and 2 . The present study results suggest that $r$ YadA shows promise as a protective antigen against yersiniosis. This study concluded that vaccination against $Y$. ptb may become available as a new method to prevent lethal epidemics in animals.

KEY WORDS: recombinant, vaccine, Yersinia adhesin A, Yersinia pseudotuberculosis

Yersiniosis is a zoonotic disease caused by Yersinia pseudotuberculosis (Y. ptb), which occurs sporadically or epidemically in many parts of the world $[14,15,25] . Y$. ptb is mainly transmitted via the oral route and causes severe acute intestinal infection, frequently accompanied by sepsis. In addition, Y. ptb forms lesions that resemble tuberculosis nodules in the liver and spleen [4].

$Y$. ptb affects various animal species and fatal cases have been reported in primates, birds, bats and rodents, as well as intensively farmed animals $[4,13,28,37,39]$. In particular, monkeys are highly susceptible to $Y$. ptb infection. In Japan, lethal epidemics have been reported in many species of monkeys in close proximity to apes and prosimians in exhibition facilities [40]. In these exhibition facilities, preventative measures against $Y$. ptb infection, including hygiene control and administration of antibiotics to carrier animals, have not been able to eliminate the epidemics. This situation represents a major hindrance to species preservation, including rare species. Under these circumstances, vaccination may be an effective preventative measure, but an effective vaccine has not yet been developed [14, 20, 25]. There are 3 Yersinia spp. that are pathogenic: Y. pestis, Y. enterocolitica and $Y$. ptb. Vaccines have been developed against $Y$. pestis, the cause of plague; although they have been used to reduce the risk of infection in endemic areas [1], the protective effects are inadequate [1, 12]. Therefore, $Y . p t b$ has been studied as an immunogen for $Y$. pestis vaccine development $[3,10]$. In addition, in New Zealand, an inactivated vaccine against $Y$. ptb is commercially available for intensively farmed animals, such as deer and cattle [26]. However, this vaccine is not available in Japan. Further, our preliminary trials using inactivated $Y$. ptb and inactivated $Y$. ptb with strong expression of Yersinia adhesin A (YadA) as immunogens in mice yielded no effect with the former vaccine and only a slight effect with the latter (private communication).

YadA is an extracellular membrane protein monomer with a molecular weight of 41-44 kilodaltons (kDa) and is encoded by the virulence plasmid (pYV). YadA is usually present as a trimer on the surface of the bacterium and has a so-called lollipop-shaped structure $[16,24,29,32,36]$. YadA has a variety of functions, such as inhibition of phagocytosis by macrophages, adhesion to intestinal epithelial cells and resistance to the bactericidal action of phagocytic cells [2,11]. Therefore, we selected YadA as a possible immunogen for a vaccine against $Y$. ptb.

*Correspondence to: Une, Y., Laboratory of Veterinary Pathology, School of Veterinary Medicine, Azabu University, 1-17-71 Fuchinobe, Chuo-ku, Sagamihara, Kanagawa 252-5201, Japan. e-mail: une@azabu-u.ac.jp

(C2017 The Japanese Society of Veterinary Science

This is an open-access article distributed under the terms of the Creative Commons Attribution Non-Commercial No Derivatives (by-ncnd) License. (CC-BY-NC-ND 4.0: https://creativecommons.org/licenses/by-nc-nd/4.o/) 
Table 1. The primer of yadA for transformation in E.coli strain BL21

\begin{tabular}{lllll}
\hline Strain & & & & \multicolumn{2}{c}{ Primer sequence $\left(5^{\prime}-3^{\prime}\right)$} \\
\hline PS & Insert & yadA & F & GGAATTCATGACTAAAGATTTTAAG \\
& & & R & CCGCTCGAGTACCACTCGATATTAAA \\
& Vector & pGEX-6P-1 & F & GGGCTGGCAAGCCACGTTTGGTG \\
& & & R & CCGGGAGCTGCATGTGTCAGAGG \\
TF & Insert & yadA & F & CCGCTCGAGATGACTAAAGATTTTAAG \\
& & & R & CGAATTCTTACCACTCGATATTAAA \\
& Vector & pCold-TF & F & CCACTTTCAACGAGCTGATG \\
& & & R & CAGAATCTAAGATCCCTGCC \\
\hline
\end{tabular}

\section{MATERIALS AND METHODS}

\section{Preparation of recombinant YadA}

In this study, YadA protein was produced using genetic recombination in Escherichia coli. The array of yadA (ACCESSION NC_010635 VERSION NC_010636.1) was obtained by analyzing the full length of 1,299 base pairs (bp) in the $Y$. ptb serotype 4b RIMD 2503048 strain (Table 1). Primers created with reference to the array of yadA were inserted into multiple cloning sites of 2 vectors: pGEX-6P-1 (TAKARA, Otsu, Japan) and pCold-TF (TAKARA). E. coli strain BL21 (DE3) (TAKARA) was implanted with the vectors, thereby producing 2 types of recombinant $E$. coli strains: PS with the pGEX-6P-1 vector and TF with the pCold-TF vector. The recombinant YadA (rYadA) proteins expressed by the 2 strains were analyzed by polyacrylamide gel electrophoresis. The rYadA of the PS strain (GST-YadA) was expressed as 67-70-kDa insoluble inclusion bodies, and the rYadA of the TF strain (His-TF-YadA) was expressed as an $89-92-k D a$ soluble component. The TF strain was purified by ultrasonic fragmentation and affinity chromatography using a His60 Ni Gravity Column (Clontech, Mountain View, CA, U.S.A.), and the PS strain was purified by ultrasonic fragmentation and centrifugation. The rYadA proteins were purified; the PS strain-derived insoluble rYadA was used as an immunogen, and the TF strain-derived soluble rYadA was used as a measurement antigen for YadA antibody in serum. The reason is that soluble rYadA derived from the TF strain could be purified with high accuracy but yields a small amount, whereas insoluble rYadA from the PS strain could be purified with low precision but the purification is easy to perform and yields a large amount.

Furthermore, to investigate the antibody reacts what domains of YadA, YadA head domain (YadA-HD) which is the domain of YadA was made and used for ELISA. The gene of YadA-HD exists from 76 to $681 \mathrm{bp}$ from the 5' of yadA and a total length is 605 bp. Also, YadA-HD exists from 26 to 227 from the N-terminal of the full-length YadA and is about 22.2 kDa [21]. The method of making up the YadA-HD expression recombinant E. coli strain (YH) was same for PS, using pGEX-6P-1 and E. coli strain BL21, the primer of YadA-HD gene was wrote in Table 1. YH was cultured performed ultrasonic disruption. Since recombinant YadA-HD was expressed as a soluble protein, the supernatant including YadA-HD purified using GSTrap FF (GE Healthcare Japan, Tokyo, Japan).

\section{Mice immunization and challenge with Y.ptb}

The immunogenicity of the 3 treatments was evaluated by the survival rate and YadA antibody titer in mice. The mice were $\mathrm{BALB} / \mathrm{c}$, male and 3 weeks of age (Japan SLC, Hamamatsu, Japan). Mice were divided into 3 groups: in group 1 ( $\mathrm{n}=5$ ), mice received PS strain-derived insoluble rYadA (100 $\mu \mathrm{g} /$ dose); in group $2(\mathrm{n}=5)$, mice received $1 \%$ formalin-inactivated $Y$. ptb serotype O4b strain RIMD2503048 with strong expression of YadA (20 mg/dose); and in group 3 ( $\mathrm{n}=3)$, mice received phosphate-buffered saline (PBS) (0.2 ml/dose). All dosages were administered subcutaneously twice at an interval of 1 week. $Y$. ptb serotype O4b strain RIMD2503048 ( $10^{7}$ cells/mouse) was administered by oral inoculation 1 week after the second administration. Mice were observed for 2 weeks, and any surviving mice were humanely killed. The survival rate and pathological findings in each group were investigated. Blood was collected from each mouse before vaccine administration and each week thereafter (a total of 4 times). The serum antibody titers in transition were measured by enzyme-linked immunosorbent assay (ELISA). The present study was carried out with the approval of the Azabu University Animal Care and Use Committee (approval number: 140303).

\section{Immunoglobulin G enzyme-linked immunosorbent assay (IgG-ELISA) for YadA antibody levels}

TF strain-derived soluble rYadA dissolved in carbonate buffer ( $\mathrm{pH} 9.4$ ) was placed in a 96-well microtiter plate at $50 \mathrm{ng} / \mathrm{well}$ and allowed to stand for $24 \mathrm{hr}$ at $4^{\circ} \mathrm{C}$; then, $300 \mu \mathrm{l}$ of blocking solution was placed in each well and allowed to stand for $15 \mathrm{~min}$. Mouse serum diluted 400 -fold with $0.05 \%$ PBS-Tween 20 (PBS-T) was added to each well at $50 \mu l /$ well. The plate was allowed to stand at room temperature for $1 \mathrm{hr}$, and then washed 5 times with PBS-T. Then, $50 \mu \mathrm{l}$ of horseradish peroxidase (HRP)-labeled anti-mouse IgG diluted 1,000-fold was placed into each well and allowed to stand for $1 \mathrm{hr}$ at room temperature. The plate was washed 5 times with PBS-T, and a coloring solution was added. Measurements were then performed using an iMark microplate reader (Bio-Rad, Hercules, CA, U.S.A.) at $405 \mathrm{~nm}$. In addition, ELISA of inactivated $Y$. ptb and YadA-HD was also performed in the same method. All the solutions and methods used were the same, inactivated $Y$. ptb coated $8 \mu \mathrm{g} /$ well of antigen and serum of mice diluted 50-fold, YadA-HD antigen coated $400 \mathrm{ng} /$ well and serum diluted 100-fold. 
a

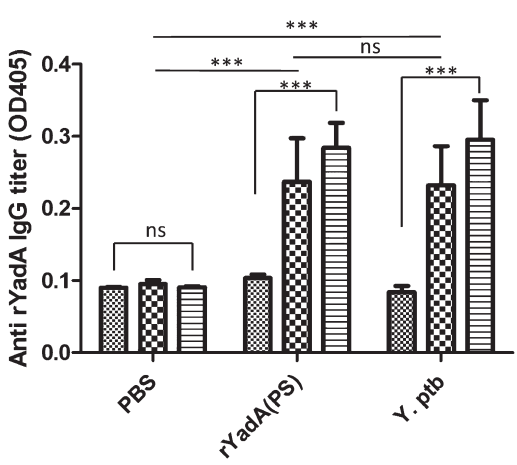

b Y. ptb specific lgG antibody titer

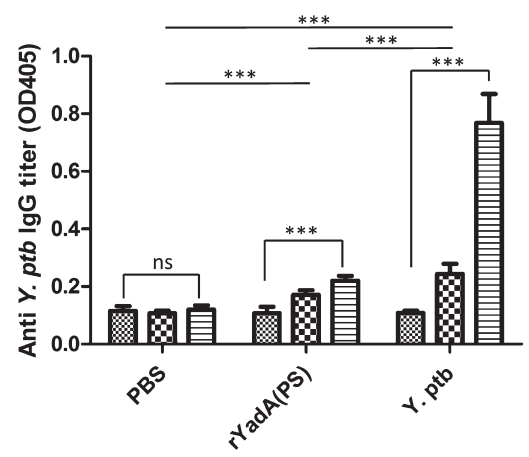

$\$$ Before

7days

E 14days

\section{YadA head domain specific IgG}

antibody titer

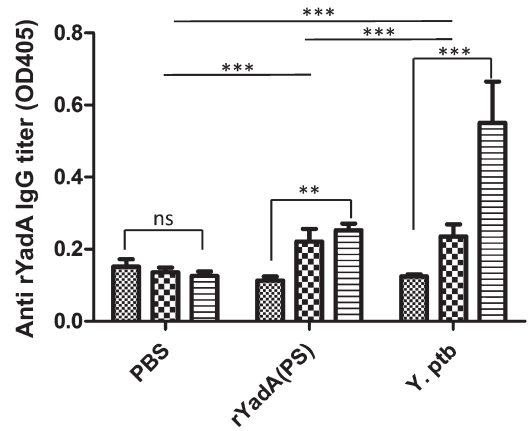

Fig. 1. Serum IgG antibody titers by ELISA in each group. The group1 was rYadA administrated mice, group2 was inactivated $Y$. ptb administrated and group3 was PBS administrated. a) The rYadA-specific IgG antibody titers are significantly elevated in the rYadA-administered group and inactivated $Y$. $p t b$-administered group $(* * * P<0.0001)$. There was no increase in antibody titer in the PBS-administered group (ns, $P=0.6124)$. Comparing antibody titers between the rYadA-administered group, $Y$. ptb-administered group and PBS-administered group, there were significant differences in the antibody titer increases in the rYadA-administered group and $Y$. ptb-administered group compared with the PBSadministered group $(* * * P=0.0002)$. On the other hand, when comparing the rYadA-administered group and $Y$. ptb-administered group, there was no significant difference in the antibody titer increases (ns, $P=0.8966)$. b) $Y$. ptb specific IgG antibody titers were significantly increased over time compared to baseline values in those groups $(* * * P<0.0001)$. Comparing antibody titers between groups 1,2 and 3 , there was a significant difference in antibody titer increases in groups 1 and 2 compared with that in group $3(* * * P=0.0001)$. Furthermore, there was significant difference in antibody titer increases between groups 1 and $2(* * * P=0.0001)$. c) YadA-HD specific IgG antibody titers were significantly increased over time compared to baseline values in those groups (group $1: * *=0.0037$, group2: $* * * P<0.0001$ ). Comparing antibody titers between groups 1,2 and 3 , there was a significant difference in antibody titer increases in groups 1 and 2 compared with that in group 3 (*** $P=0.0001)$. Furthermore, there was significant difference in antibody titer increases between groups 1 and $2(* * * P=0.0001)$.

\section{Pathological examination}

Dead and sacrificed mice underwent an autopsy and macroscopic examination. Sampled heart, lung, liver, spleen, jejunum, ileum, cecum and colon specimens were fixed in 10\% phosphate-buffered formalin solution, paraffin-embedded and sectioned in 3-4- $\mu \mathrm{m}$ slices using conventional methods. Then, hematoxylin-eosin (HE) staining was performed for histopathological observation. Furthermore, samples were immunohistochemically searched using rabbit anti- $Y$. ptb O4 antibody ( $\times 400$, Trypsin) (Denka Seiken, Tokyo, Japan) and horseradish peroxidase (HRP)-labeled goat anti-rabbit antibody (Nichirei Biosciences, Tokyo, Japan) by the conventional method.

\section{Statistical analysis}

Serum IgG antibody titers of mice were compared with a two-way repeated-measures analysis of variance (ANOVA) test and a one-way ANOVA test, and the survival of mice was compared with the Kaplan-Meier test. For both tests, GraphPad Prism 5 (GraphPad Software, La Jolla, CA, U.S.A.) was used.

\section{RESULTS}

\section{Serum YadA-specific IgG antibody titers}

In groups 1 and 2, anti-YadA specific IgG antibody titers in the serum were significantly increased over time compared to baseline values in those groups (Fig. 1a) $(P<0.0001)$. Also $Y$. ptb specific IgG antibody titers were increased (Fig. 1b) $(P<0.0001)$, and rYadA-HD specific IgG antibody titers were significantly increased (Fig. 1c) (group1: $P=0.0037$, and group2: $P<0.0001$ ). The average of rYadA in group 1 increased from 0.103 to $0.301, Y$. ptb increased from 0.107 to 0.220 and rYadA-HD increased from 0.113 to 0.252 and the values of rYadA in group 2 were 0.083 to 0.295 , those of $Y$. ptb were 0.108 and 0.773 and those of rYadAHD were 0.124 to 0.550 at 0 days to 14 days, respectively (Fig. 1a-1c). There were no increase in the antibody titers of rYadA, $Y$. $p t b$ and rYadA-HD in group 3 (rYadA; $P=0.6124, Y$. ptb; $P=0.6124$, rYadA-HD; P-0.5152). In addition, when comparing antibody titers of rYadA, $Y$. ptb and rYadA-HD between groups 1, 2 and 3, there were significant differences in antibody titer increases in groups 1 and 2 compared with that in group 3 (rYadA; $P=0.0002, Y$. ptb, rYadA-HD; $P=0.0001$ ). On the other hand, there was no significant difference in antibody titer of rYadA increases between groups 1 and $2(P=0.8966)$. But there was significant difference in antibody titers of $Y$. $p t b$ and rYadA-HD increases between groups 1 and $2(P=0.0001)$. 


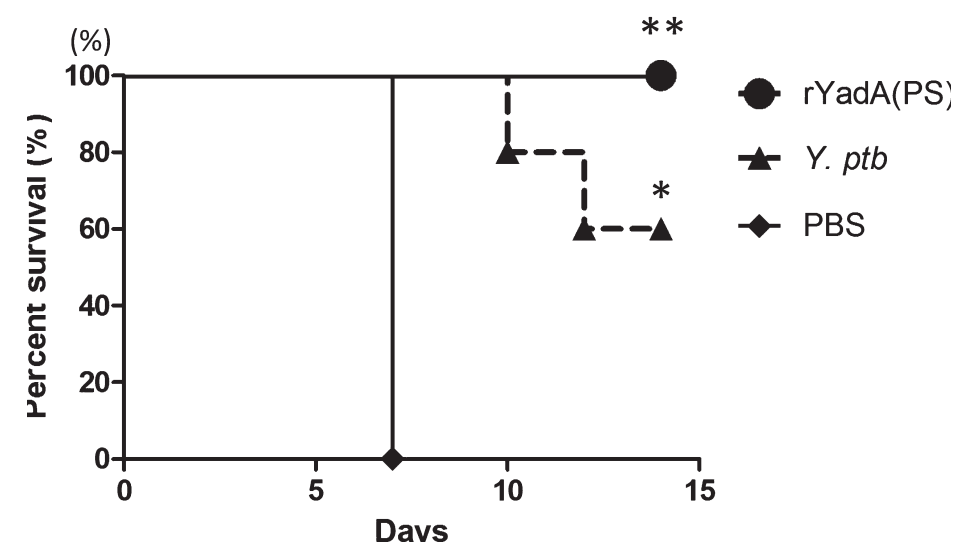

Fig. 2. Survival rate in each group. The survival rate is significantly increased in the rYadA-administered group $(100 \% ; * * P=0.0044)$ and inactivated $Y$. $p t b$-administered group $\left(60 \%\right.$; $\left.{ }^{*} P=0.0121\right)$. On the other hand, the survival rate of the PBS-administered group is $0 \%$.
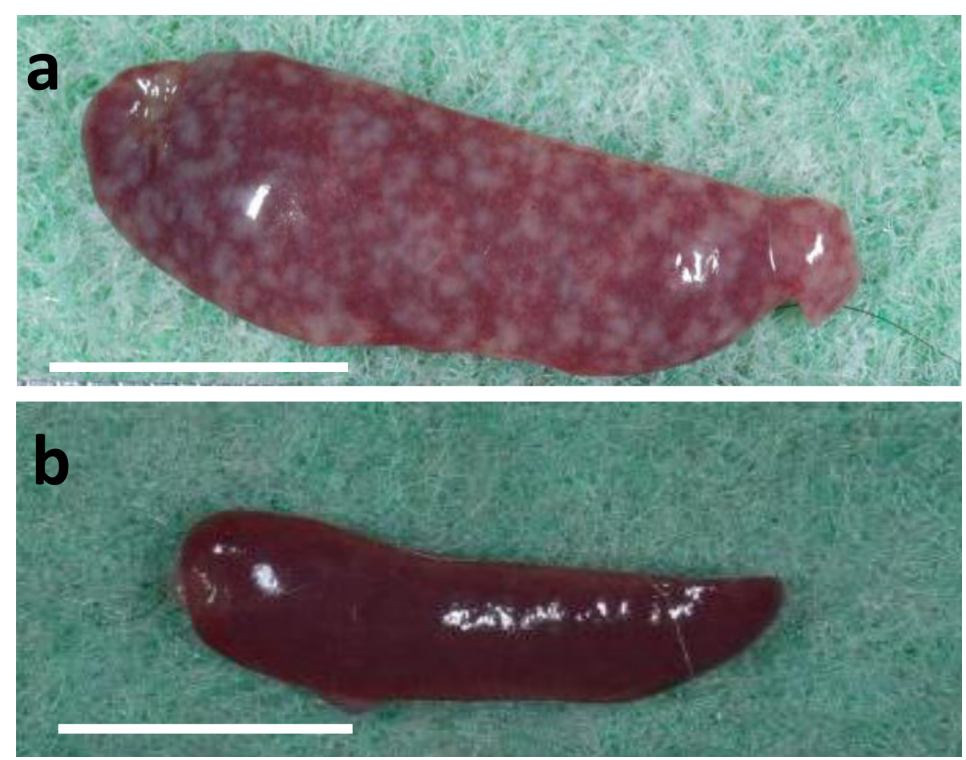

Fig. 3. Comparison of the gross lesions. a) The spleen of a non-surviving mouse in the group administered PBS. As was the case in all the mice that died during the observation period, the spleen shows marked enlargement and a large number of small white nodules. b) The spleen of a surviving mouse in the group administered rYadA. As was the case in mice that survived the $Y$. ptb infection, the spleen shows mild-to-moderate enlargement. Although white nodules are observed, this was not the case in all the surviving mice.

\section{Clinical symptoms and survival}

The survival rate after $Y$. ptb infection was $100 \%$ in group 1, 60\% in group 2 and $0 \%$ in group 3 (Fig. 2). The fur of mice inoculated with $Y$. ptb appeared dull and ruffled from day 4. All mice in group 3 and 2 mice in group 2 showed reduced vitality, a hunched posture and depression, and died between day 7 and day 13 after $Y$. ptb inoculation. No clinical abnormalities were observed during the immunization period and no side effects resulted from vaccine administration.

\section{Pathological findings}

In all 5 mice that did not survive, marked enlargement of the spleen, Peyer's patches and mesenteric lymph nodes were grossly visible; in addition, the spleen and liver showed numerous multifocal white nodules (Fig. 3a). On the other hand, in surviving mice, the spleen and liver lesions were mild, but the enlargement of the Peyer's patches and mesenteric lymph nodes were comparable to those in the non-surviving mice (Fig. 3b).

On histological examination, the non-surviving mice displayed severe necrotic lesions with $Y$. ptb growth. In the spleen and liver, consistent with the white nodules, areas of severe necrosis were observed with colonies of $Y$. ptb in the center and with surrounding inflammatory cell infiltration consisting mainly of neutrophils (Fig. 4a and 4c). Additionally, in the liver, small foci of inflammation consisting of a small number of inflammatory cells, mainly neutrophils, were observed. Peyer's patches were almost 

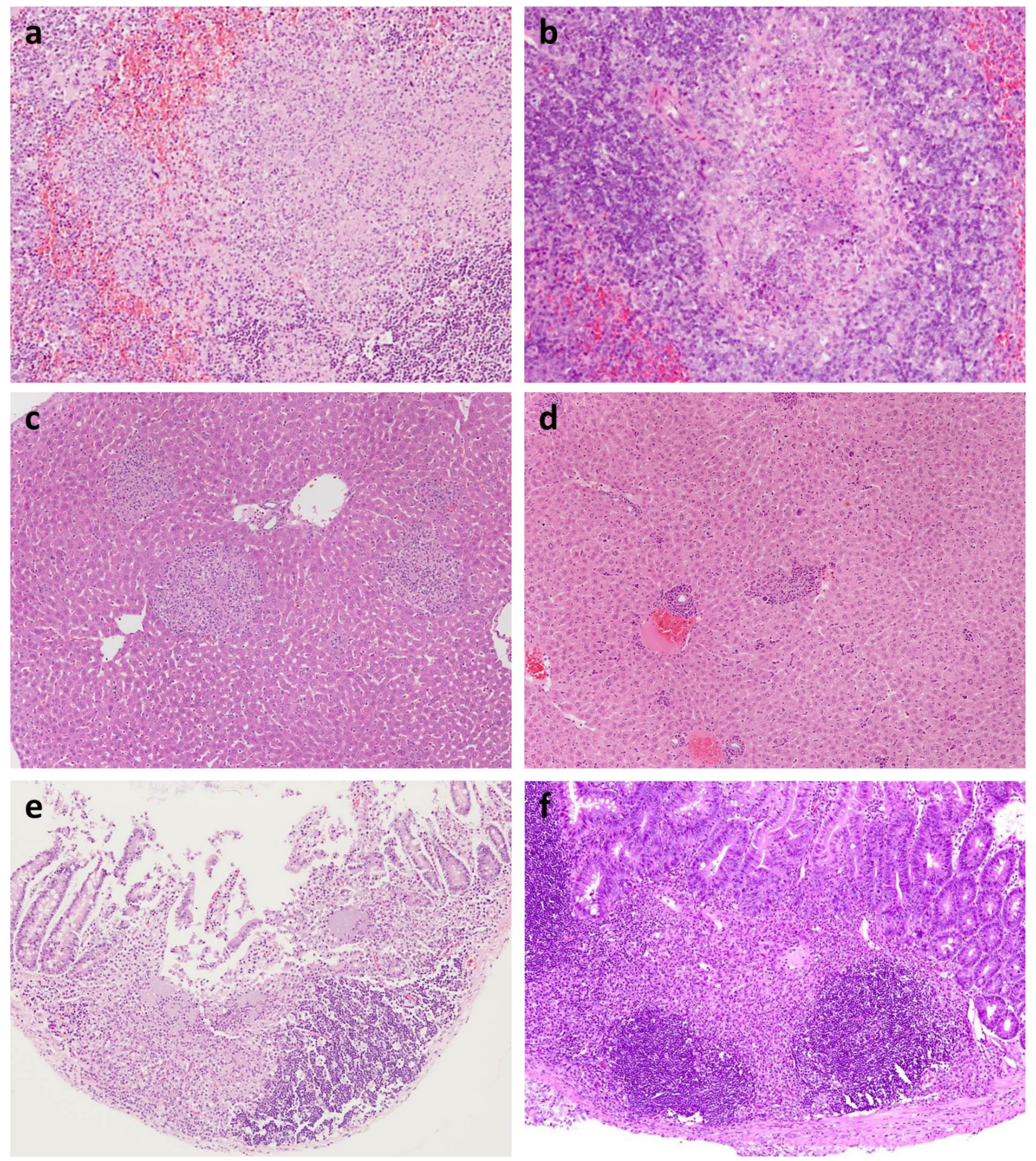

Fig. 4. Comparisons of histological lesions. a) The spleen of a non-surviving mouse in the group administered PBS. Lymphoid follicles are substantially reduced in size and the number of lymphocytes is decreased. In addition, a large number of severe necrotic foci containing $Y$. ptb colonies are observed $(\mathrm{Bar}=100 \mu \mathrm{m})$. b) The spleen of a surviving mouse in the group administered rYadA. Scattered moderate necrotic foci containing $Y$. ptb colonies are observed, and the surrounding tissue is organized. In addition, infiltration by mainly macrophages, lymphocytes and fibroblasts is seen at the periphery of the necrotic foci $(\mathrm{Bar}=100 \mu \mathrm{m})$. c) The liver of a non-surviving mouse in the group administered PBS. Numerous large and small severe multifocal necrotic foci are observed (Bar=100 $\mu \mathrm{m})$. d) The liver of a surviving mouse in the group administered rYadA. A limited number of small areas of granulomatous inflammation without necrosis and large areas of granulomatous inflammation with necrosis are observed (Bar=100 $\mu \mathrm{m})$. e) Peyer's patches in a non-surviving mouse in the group administered PBS. Severe necrotic foci containing Y. ptb colonies are observed. Mucosal epithelial cells display necrosis and exfoliation, and infiltration of neutrophils is seen in the gut lamina propria mucosae (Bar $=100 \mu \mathrm{m})$. f) Peyer's patches in a surviving mouse in the group administered rYadA. Scattered moderate necrotic foci and infiltration by mainly macrophages, lymphocytes and fibroblasts are seen (Bar=100 $\mu \mathrm{m})$. 
replaced by necrotic tissue containing $Y$. ptb colonies. The mucosal epithelial cells of the small intestine, cecum, and colon were necrotic and exfoliated (Fig. 4e).

In the surviving mice, the necrotic lesions were mild, and granuloma formation and cellular tissue repair reactions were advanced. The spleen had a small number of mild necrotic foci with $Y$. ptb colonies, and organization and infiltration of mainly fibroblasts, macrophages and lymphocytes were present around these necrotic foci (Fig. 4b). In the liver, a small granuloma without necrosis and a small number of granulomas with necrosis were observed (Fig. 4d). Peyer's patches were interspersed with moderate necrotic foci, but the tissue surrounding these foci was organized (Fig. 4f). Immunohistochemically, $Y$. ptb was found in large amounts in the spleens, livers and Peyer's patches of all dead mice (Fig. 5a, 5c and 5e). On the other hand, in the surviving mice, no bacteria were found in the spleens or livers (Fig. $5 \mathrm{~b}$ and $5 \mathrm{~d}$ ). However, in some surviving mice, $Y$. ptb was present in a mild-to-moderate amount in the Peyer's patch of the small intestine (Fig. 5f).

\section{DISCUSSION}

In the present study, we aimed to determine possible immunogens for a vaccine against $Y$. ptb by investigating the survival rate and serum antibody levels of mice inoculated with inactivated $Y$. ptb with strong expression of YadA, rYadA or PBS. Of note, the mice that received inactivated $Y$. pt $b$ or rYadA had significantly elevated anti- $Y$. ptb antibody levels and all the mice that received rYadA survived. Moreover, according to the pathological findings, serum YadA-specific IgG prevented the spread of $Y$. ptb that invaded the body as a mechanism to prevent lethal lesions caused by $Y$. ptb infection. There were many cells targeted by $Y$. $p t b$ in the organs, which adhered to them via YadA and resulted in pathogenicity. We believed that their activity could not lead to death because of the presence of YadA-specific IgG. However, rYadA could not induce mucosal immunity, so rYadA could not defend against $Y$. ptb invasion in the intestine.

In the pathogenesis of yersiniosis, the $Y$. ptb organisms infect the host via the oral route and adhere to the $\mathrm{M}$ cells of the intestinal Peyer's patches. They then infiltrate into the tissue and grow proliferously. Subsequent hematogenous spread to various organs results in the formation of necrotic lesions and sepsis, which is frequently lethal [18]. Pathogenic $Y$. ptb factors involved in the formation of these lesions include YadA and Yersinia outer membrane proteins (Yops) encoded by virulence plasmid DNA, and invasin and $Y$. ptb-derived mitogen encoded by chromosomal DNA. YadA, although not cytotoxic itself, has various functions in the pathogenesis of disease, such as enabling Y. ptb to adhere to target cells and inhibiting phagocytosis by host cells [2, 11].

Vaccine development for the control of yersiniosis has been studied previously. Vaccines that target the LcrV and invasin proteins related to the type III secretion system have been considered, but not yet put into practical use [6, 34, 35]. Furthermore, we previously obtained no effects with either formalin-inactivated $Y$. ptb or Yops used as immunogens in preliminary experiments (private communication). In another study reporting a recombinant vaccine for $Y$. ptb, Daniel et al. showed high survival rates while maintaining high safety using Lactobacillus lactis [9]. However, the survival rate was 55\% to $80 \%$ despite the small number of $Y$. ptb bacteria in the challenge $\left(10^{3}\right)$, and all mice that died were dead within 2 weeks after the challenge. In addition, about $10^{6} Y$. ptb were detected in the spleen and liver after the observation period. However, we did not perform long-term observations for the vaccine we developed and used fewer mice than Daniel et al. Therefore, while it could not be determined clearly, but the survival rate was $100 \%$ despite a $10^{7}$ Y. ptb challenge and no Y. ptb were detected immunohistochemically in the spleen or liver, so it was considered to be superior in these points. YadA was used as an immunogen in this study, and subcutaneous administration (twice at an interval of 1 week) of inactivated $Y$. ptb with strong expression of YadA and rYadA yielded survival rates of $60 \%$ and $100 \%$, respectively, with no observed side effects from the vaccination. In addition, although inactivated vaccines generally have low immunogenicity compared with live attenuated vaccines and require immune enhancement with the use of multiple doses or adjuvants $[5,7,23]$, we found that inoculation twice with rYadA without an immune-enhancing agent appeared to generate a sufficient serum rYadA-specific IgG antibody titer to prevent lethal infection in mice. Surviving mice exhibited mild lesions, which mostly consisted of organizing tissue. We considered that rYadA could not defend in organisms from infecting and growing in the mucosa but could reduce hematogenous spread and the risk of sepsis, resulting in $Y$. ptb lesions that were not severe. These results suggest that subcutaneous administration of rYadA generates sufficient serum rYadA-specific IgG antibody in mice to prevent sepsis due to $Y$. ptb; therefore, rYadA may be useful as a vaccine immunogen. On the other hand, although there was no significant difference between inactivated $Y$. ptb and rYadA antibody titers, there was a difference in survival rate. And there were significantly differences in the antibody titers of $Y$. $p t b$ and YadA-HD. And therefore, two possibilities were considered. The first possibility is that immunity may have been enhanced by some action by some antigen present in recombinant E. coli, not present in $Y$. ptb. We found that antibodies to only the antigen of $Y$. ptb were insufficient as immunogens because dead mice appeared even the antibody titer of $Y$. ptb was high. The second possibility is that domains other than YadA-HD, membrane anchor, coiled coil segment, stalk or neck may have been important as immunogens. YadA-HD is the domain that first adheres to target cells [21, 29]. Therefore, we had an idea that many of the functions of YadA required YadA-HD, and it was highly useful as the immunogen, but that idea was different because rYadA-HD antibody titer was significant difference between rYadA administered group and inactivated $Y$. $p t b$ administered group. Since the functions of each domain have not yet been reported, so we could not investigate and perform ELISA for domains other than YadA-HD, so we could not identify important antigens against $Y$. ptb infection. These antigens will be the subject of further studies.

A wide variety of animals is sensitive to the effects of $Y$. $p t b$, and lethal yersiniosis has been reported in species, such as the parakeet, maple butterfly, marmot, bat, toucan and squirrel monkey [8, 19, 27, 28, 30, 31]. In addition, cases of infection in humans have been reported in recent years $[22,38]$. Y. ptb is carried by the pig, wild rodents and birds, making prevention of intrusion by 


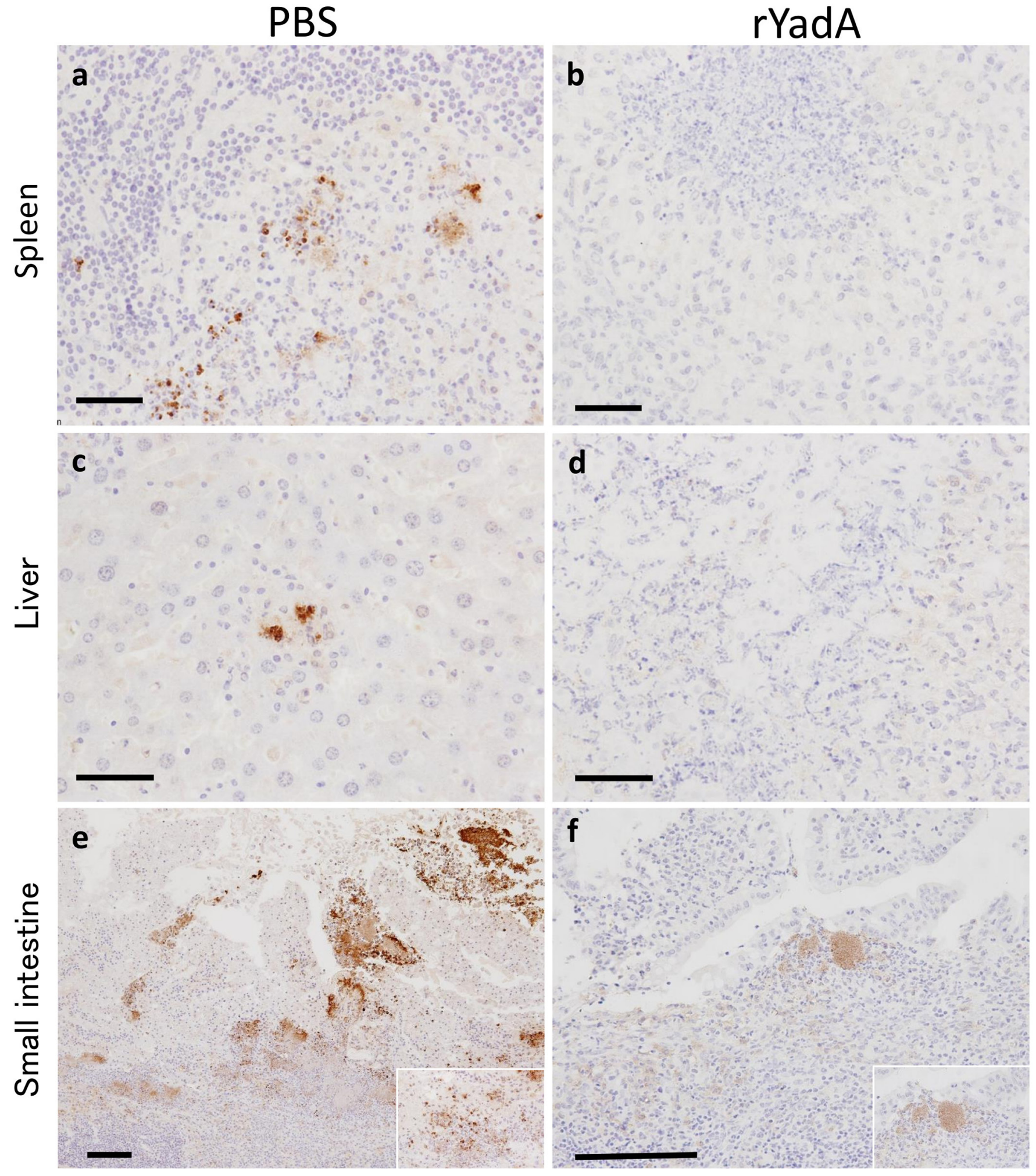

Fig. 5. Comparisons of immunohistochemical findings. a) The spleen of a non-surviving mouse from the group administered PBS. In severe necrotic foci, there are many $Y$. ptb positive for anti- $Y$. ptb $\mathrm{O} 4$ antibody $(\mathrm{Bar}=20 \mu \mathrm{m})$. b) The spleen of a surviving mouse from the group administered rYadA. In infiltrates and necrotic foci, there are no $Y$. ptb positive for anti- $Y$. ptb $\mathrm{O} 4$ antibody (Bar=20 $\mu \mathrm{m})$. c) The liver of a non-surviving mouse from the group administered PBS. In infiltrates and severe necrotic foci, there are many $Y$. ptb positive for anti-Y. ptb O4 antibody $(\mathrm{Bar}=20 \mu \mathrm{m})$. d) The liver of a surviving mouse from the group administered rYadA. In infiltrates, there is no $Y$. $p t b$ positive for anti- $Y$. $p t b \mathrm{O} 4$ antibody $(\mathrm{Bar}=20 \mu \mathrm{m})$. e) Peyer's patches in a non-surviving mouse from the group administered PBS. In necrotic foci of the intestinal epithelium, lamina propria and mucosal muscle layer, many $Y$. ptb are positive for anti- $Y$. ptb O4 antibody (Bar=100 $\mu$ m). f) Peyer's patches in a surviving mouse from the group administered rYadA. In infiltrates from the intestinal epithelium, lamina propria and mucosal muscle layer, there are mild-to-moderate numbers of $Y$. ptb positive for anti-Y. ptb O4 antibody (Bar=100 $\mu \mathrm{m}$ ). 
carrier animals very difficult in animal breeding facilities [17, 33]. In addition, once an animal in the facility is infected, it may serve as a source of infection for all the animals in the breeding facility, resulting in an epidemic. Therefore, there is an urgent need to establish a means to prevent infection. As mentioned previously, results with the rYadA vaccine in mice suggest that this immunogen may be used to generate sufficient antibody levels to prevent sepsis due to $Y$. ptb. In addition, it is not necessary to handle pathogenic bacteria when producing the rYadA vaccine because of the use of recombinant $E$. coli and it is possible to produce the vaccine in a relatively short time, thereby facilitating stability and mass culture. Therefore, use of rYadA as a vaccine immunogen may contribute greatly to the prevention of yersiniosis. However, in the study by Zhang et al., although the survival rate of the mice was good, they reported that $Y$. ptb was detected in internal organs after the observation period, so the mice were possibly carrier animals [41]. In our study, Y. ptb was not detected in the spleen or liver by immunohistochemistry, but the immunohistochemical method has low detection sensitivity. Therefore, subclinical infection due to vaccine administration is conceivable. It is necessary to conduct a long-term investigation in the future, determine the amount of $Y$. ptb in the feces and determine the colonization mechanism.

In conclusion, the present study results revealed that rYadA may be a useful immunogen for vaccine development as a valid defense method against yersiniosis caused by $Y$. ptb. In this study, it was possible to confer a high protective effect against sepsis due to $Y$. ptb. in the sensitive mouse by inoculation with an rYadA vaccine. This is a first step in the prevention of $Y$. ptb infection and may be considered a breakthrough result that could be applied to vaccine production in this country for the prevention of yersiniosis in a variety of animal species.

\section{REFERENCES}

1. BC Centre for Disease Control online. http://www.bccdc.ca/health-info/diseases-conditions/yersinia-infection (accessed Oct 12, 2016).

2. Bi, Y., Wang, X., Han, Y., Guo, Z. and Yang, R. 2012. Yersinia pestis versus Yersinia pseudotuberculosis: effects on host macrophages. Scand. J. Immunol. 76: 541-551. [Medline] [CrossRef]

3. Blisnick, T., Ave, P., Huerre, M., Carniel, E. and Demeure, C. E. 2008. Oral vaccination against bubonic plague using a live avirulent Yersinia pseudotuberculosis strain. Infect. Immun. 76: 3808-3816. [Medline] [CrossRef]

4. Bronson, R. T., May, B. D. and Ruebner, B. H. 1972. An outbreak of infection by Yersinia pseudotuberculosis in nonhuman primates. Am. J. Pathol. 69: 289-308. [Medline]

5. Brown, R. C., Hendley, J. O. and Gwaltney, J. M. Jr. 1972. Mycoplasma pneumoniae vaccine: antigenicity of buffered antigens in volunteers. Infect. Immun. 5: 657-661. [Medline]

6. Brubaker, R. R. 2003. Interleukin-10 and inhibition of innate immunity to Yersiniae: roles of Yops and LcrV (V antigen). Infect. Immun. 71: 3673-3681. [Medline] [CrossRef]

7. Burgasov, P. N., Sumarokov, A. A., Lelikov, V. L., Marcuk, L. M., Fedenev, V. G., Dzaparidze, M. N., Karaeva, L. T. and Derteva, I. I. 1976. Comparative study of reactions and serological response to cholera vaccines in a controlled field trial conducted in the USSR. Bull. World Health Organ. 54: 163-170. [Medline]

8. Childs-Sanford, S. E., Kollias, G. V., Abou-Madi, N., McDonough, P. L., Garner, M. M. and Mohammed, H. O. 2009. Yersinia pseudotuberculosis in a closed colony of Egyptian fruit bats (Rousettus aegyptiacus). J. Zoo Wildl. Med. 40: 8-14. [Medline] [CrossRef]

9. Daniel, C., Titecat, M., Poiret, S., Cayet, D., Boutillier, D., Simonet, M., Sirard, J. C., Lemaître, N. and Sebbane, F. 2016. Characterization of the protective immune response to Yersinia pseudotuberculosis infection in mice vaccinated with an LcrV-secreting strain of Lactococcus lactis. Vaccine 34: 5762-5767. [Medline] [CrossRef]

10. Derbise, A., Cerdà Marín, A., Ave, P., Blisnick, T., Huerre, M., Carniel, E. and Demeure, C. E. 2012. An encapsulated Yersinia pseudotuberculosis is a highly efficient vaccine against pneumonic plague. PLoS Negl. Trop. Dis. 6: e1528. [Medline] [CrossRef]

11. Eitel, J. and Dersch, P. 2002. The YadA protein of Yersinia pseudotuberculosis mediates high-efficiency uptake into human cells under environmental conditions in which invasin is repressed. Infect. Immun. 70: 4880-4891. [Medline] [CrossRef]

12. Feodorova, V. A. and Motin, V. L. 2012. Plague vaccines: current developments and future perspectives. Emerg. Microbes Infect. 1: e36. [Medline] [CrossRef]

13. Fukushima, H. and Gomyoda, M. 1991. Intestinal carriage of Yersinia pseudotuberculosis by wild birds and mammals in Japan. Appl. Environ. Microbiol. 57: 1152-1155. [Medline]

14. Fukushima, H., Matsuda, Y., Seki, R., Tsubokura, M., Takeda, N., Shubin, F. N., Paik, I. K. and Zheng, X. B. 2001. Geographical heterogeneity between Far Eastern and Western countries in prevalence of the virulence plasmid, the superantigen Yersinia pseudotuberculosis-derived mitogen, and the high-pathogenicity island among Yersinia pseudotuberculosis strains. J. Clin. Microbiol. 39: 3541-3547. [Medline] [CrossRef]

15. Galindo, C. L., Rosenzweig, J. A., Kirtley, M. L. and Chopra, A. K. 2011. Pathogenesis of Y. enterocolitica and Y. pseudotuberculosis in Human Yersiniosis. J. Pathogens 2011: 182051. [Medline] [CrossRef]

16. Gripenberg-Lerche, C., Skurnik, M. and Toivanen, P. 1995. Role of YadA-mediated collagen binding in arthritogenicity of Yersinia enterocolitica serotype O:8: experimental studies with rats. Infect. Immun. 63: 3222-3226. [Medline]

17. Hamasaki, S., Hayashidani, H., Kaneko, K., Ogawa, M. and Shigeta, Y. 1989. A survey for Yersinia pseudotuberculosis in migratory birds in coastal Japan. J. Wildl. Dis. 25: 401-403. [Medline] [CrossRef]

18. Hanski, C., Naumann, M., Hahn, H. and Riecken, E. O. 1989. Determinants of invasion and survival of Yersinia enterocolitica in intestinal tissue. An in vivo study. Med. Microbiol. Immunol. (Berl.) 178: 289-296. [Medline] [CrossRef]

19. Harcourt-Brown, N. H. 1978. Yersinia pseudotuberculosis infection in birds. Vet. Rec. 102: 315. [Medline] [CrossRef]

20. Hirai, K., Suzuki, Y., Kato, N., Yagami, K. and Miyoshi, A. 1974. Yersinia pseudotuberculosis infection occurred spontaneously in a group of patas monkeys (Erythrocebus patas). Nippon Juigaku Zasshi 36: 351-355. [Medline] [CrossRef]

21. Hoiczyk, E., Roggenkamp, A., Reichenbecher, M., Lupas, A. and Heesemann, J. 2000. Structure and sequence analysis of Yersinia YadA and Moraxella UspAs reveal a novel class of adhesins. EMBO J. 19: 5989-5999. [Medline] [CrossRef]

22. Inoue, M., Nakashima, H., Ishida, T. and Tsubokura, M. 1988. Three outbreaks of yersinia pseudotuberculosis infection. Zentralbl. Bakteriol. Mikrobiol. Hyg. [B] 186: 504-511. [Medline] 
23. Lundgren, A., Bourgeois, L., Carlin, N., Clements, J., Gustafsson, B., Hartford, M., Holmgren, J., Petzold, M., Walker, R. and Svennerholm, A. M. 2014. Safety and immunogenicity of an improved oral inactivated multivalent enterotoxigenic Escherichia coli (ETEC) vaccine administered alone and together with dmLT adjuvant in a double-blind, randomized, placebo-controlled Phase I study. Vaccine 32: 7077-7084. [Medline] [CrossRef]

24. Mack, D., Heesemann, J. and Laufs, R. 1994. Characterization of different oligomeric species of the Yersinia enterocolitica outer membrane protein YadA. Med. Microbiol. Immunol. (Berl.) 183: 217-227. [Medline] [CrossRef]

25. Mair, N. S. 1973. Yersiniosis in wildlife and its public health implications. J. Wildl. Dis. 9: 64-71. [Medline] [CrossRef]

26. Meinzer, U., Barreau, F., Esmiol-Welterlin, S., Jung, C., Villard, C., Léger, T., Ben-Mkaddem, S., Berrebi, D., Dussaillant, M., Alnabhani, Z., Roy, M., Bonacorsi, S., Wolf-Watz, H., Perroy, J., Ollendorff, V. and Hugot, J. P. 2012. Yersinia pseudotuberculosis effector YopJ subverts the Nod2/ RICK/TAK1 pathway and activates caspase-1 to induce intestinal barrier dysfunction. Cell Host Microbe 11: 337-351. [Medline] [CrossRef]

27. Nakamura, S., Hayashidani, H., Iwata, T., Takada, M. and Une, Y. 2009. Spontaneous Yersiniosis due to Yersinia pseudotuberculosis serotype 7 in a squirrel monkey. J. Vet. Med. Sci. 71: 1657-1659. [Medline] [CrossRef]

28. Nakamura, S., Settai, S., Hayashidani, H., Urabe, T., Namai, S. and Une, Y. 2013. Outbreak of yersiniosis in Egyptian rousette bats (Rousettus aegyptiacus) caused by Yersinia pseudotuberculosis serotype 4b. J. Comp. Pathol. 148: 410-413. [Medline] [CrossRef]

29. Nummelin, H., Merckel, M. C., Leo, J. C., Lankinen, H., Skurnik, M. and Goldman, A. 2004. The Yersinia adhesin YadA collagen-binding domain structure is a novel left-handed parallel beta-roll. EMBO J. 23: 701-711. [Medline] [CrossRef]

30. Plankina, Z. A. and Ogneva, N. S. 1961. [A case of the isolation of the pseudotuberculosis pathogen from Marmota baibacina]. Zh. Mikrobiol. Epidemiol. Immunobiol. 32: 124-127 (in Russian). [Medline]

31. Sanekata, T., Yoshikawa, N., Otsuki, K. and Tsubokura, M. 1991. Yersinia pseudotuberculosis isolation from cockatoo. J. Vet. Med. Sci. 53: 121-122. [Medline] [CrossRef]

32. Shahid, S. A., Markovic, S., Linke, D. and van Rossum, B. J. 2012. Assignment and secondary structure of the YadA membrane protein by solidstate MAS NMR. Sci. Rep. 2: 803. [Medline] [CrossRef]

33. Shiozawa, K., Hayashi, M., Akiyama, M., Nishina, T., Nakatsugawa, S., Fukushima, H. and Asakawa, Y. 1988. Virulence of Yersinia pseudotuberculosis isolated from pork and from the throats of swine. Appl. Environ. Microbiol. 54: 818-821. [Medline]

34. Sing, A., Reithmeier-Rost, D., Granfors, K., Hill, J., Roggenkamp, A. and Heesemann, J. 2005. A hypervariable N-terminal region of Yersinia LcrV determines Toll-like receptor 2-mediated IL-10 induction and mouse virulence. Proc. Natl. Acad. Sci. U.S.A. 102: 16049-16054. [Medline] [CrossRef]

35. Sing, A., Rost, D., Tvardovskaia, N., Roggenkamp, A., Wiedemann, A., Kirschning, C. J., Aepfelbacher, M. and Heesemann, J. 2002. Yersinia V-antigen exploits toll-like receptor 2 and CD14 for interleukin 10-mediated immunosuppression. J. Exp. Med. 196: 1017-1024. [Medline] [CrossRef]

36. Tamm, A., Tarkkanen, A. M., Korhonen, T. K., Kuusela, P., Toivanen, P. and Skurnik, M. 1993. Hydrophobic domains affect the collagen-binding specificity and surface polymerization as well as the virulence potential of the YadA protein of Yersinia enterocolitica. Mol. Microbiol. 10: 995-1011. [Medline] [CrossRef]

37. Tsubokura, M., Otsuki, K., Kawaoka, Y. and Maruyama, T. 1984. Characterization and pathogenicity of Yersinia pseudotuberculosis isolated from swine and other animals. J. Clin. Microbiol. 19: 754-756. [Medline]

38. Tsubokura, M., Otsuki, K., Sato, K., Ouchi, K., Tanaka, M., Hongo, T., Fukushima, H. and Inoue, M. 1987. [Distribution of Yersinia pseudotuberculosis in Japan and epidemiology of human infection]. Kansenshogaku Zasshi 61: 737-745 (in Japanese). [Medline] [CrossRef]

39. Uchida, I., Kaneko, K. and Hashimoto, N. 1982. Cross-protection against fecal excretion of Yersinia enterocolitica and Yersinia pseudotuberculosis in mice by oral vaccination of viable cells. Infect. Immun. 36: 837-840. [Medline]

40. Une, Y. 2011. Yersiniosis. pp.22-24. In: Monkeys of the Disease Color Atlas. Preventive Health Association. (in Japanese)

41. Zhang, Y., Mena, P., Romanov, G., Lin, J. S., Smiley, S. T. and Bliska, J. B. 2012. A protective epitope in type III effector YopE is a major CD8 T cell antigen during primary infection with Yersinia pseudotuberculosis. Infect. Immun. 80: 206-214. [Medline] [CrossRef] 